\title{
Axonal Guidance and the Development of Muscle Fiber-Specific Innervation in Drosophila Embryos
}

\author{
Jørgen Johansen," Marnie E. Halpern, and Haig Keshishian \\ Department of Biology, Yale University, New Haven, Connecticut 06511
}

The outgrowth of peripheral nerves and the development of muscle fiber-specific neuromuscular junctions were examined in Drosophila embryos using immunocytochemistry and computer-enhanced digital optical microscopy. We find that the pioneering of the peripheral nerves and the formation of the neuromuscular junctions occur through a precisely orchestrated sequence of stereotyped axonal trajectories, mediated by the selective growth cone choices of pioneer motoneurons. We have also examined the establishment of the embryonic muscle fibers and, using intracellular dye fills, have identified cells that are putative muscle pioneers. The muscle fibers of the bodywall have completed their morphogenesis prior to the initiation of synaptic contacts, and owing to the timing of neurite outgrowth from the CNS, synaptogenesis is synchronous at muscle fibers throughout the bodywall. At each muscle fiber the innervating axons make their initial contacts on a characteristic surface domain of the target cell's membrane. Through stereotyped growth cone-mediated trajectories the motoneurons actively establish the basic anatomical features of the mature neuromuscular junction, including the stereotyped, muscle flber-specific branch anatomy. These events occur without significant process pruning or apparent synapse elimination. Our results suggest that the basic elements of the mature neuromuscular innervation, including the details of the ending trajectory on the target cell's surface, are formed by the precise navigation and presumed recognition by the motoneuron growth cones of muscle membrane surface features.

Embryonic axons must pioneer novel pathways both within the central nervous system and to and from the periphery. In both vertebrates (Jessel, 1988) and invertebrates (Goodman et al., 1984; Keshishian, 1987; Harrelson and Goodman, 1988) the pioneering axonal projections are often the product of highly stereotyped growth cone behavior, guiding the axons to the vicinity of their proper synaptic targets where selective and specific contacts are made. Among the mechanisms thought to assist in neuronal recognition and in the guidance of pioneering

\footnotetext{
Received Mar. 9, 1989; revised June 7, 1989; accepted June 13, 1989.

We are grateful to Drs. P. Petrusz and C. Toomim for generously providing us with the glutamate-specific antiserum. We also thank Drs. John Carlson and Robert Wyman for helpful comments with the manuscript. This work was supported by grants from the NIH, March of Dimes and McKnight Foundation (H.K.), a NIMH training grant (J.J.), and a NIMH Pre-doctoral Fellowship (M.E.H.).

Correspondence should be addressed to Haig Keshishian, Biology Department, Yale University, P.O. Box 6666 KBT, New Haven, CT 06511.

a Present address: Department of Zoology, Science Bldg. II, Iowa State University, Ames, IA 50011.

Copyright (C) 1989 Society for Neuroscience $0270-6474 / 89 / 124318-15 \$ 02.00 / 0$
}

axons over uncharted embryonic landscapes are the recognition of(1) guidepost neurons and glia (Bentley and Keshishian, 1982; Bastiani and Goodman, 1986), (2) epithelial gradients (Nardi, 1983), (3) segmental borders (Bentley and Caudy, 1983), and (4) the dynamic expression of surface molecules on labeled axonal pathways and target cells (Harrelson and Goodman, 1988). To date most of our understanding of neuronal guidance and recognition in vivo has been based on the behavior of elongating neurites over very complex embryonic substrates, such as the CNS neuropil. In this report we describe the development of innervation of a simple and accessible neuromuscular system in the embryo of the fruitfly, Drosophila melanogaster.

In Drosophila embryos and larvae the musculature consists of a segmentally repeated pattern composed of 31 or fewer discrete unicellular muscle fibers per hemisegment (Hertweck, 1931; Jan and Jan, 1976; Crossley, 1978; Campos-Ortega and Hartenstein, 1985; Anderson et al., 1988). We have recently shown that in third instar larvae each of the identifiable muscle fibers is innervated by motoneurons expressing glutamate as a transmitter and that the neuromuscular junctions are anatomically stereotyped, with muscle fiber-specific branching patterns (Johansen et al., 1989). One likely mechanism to account for this high degree of precision in neuromuscular connectivity is that each muscle cell is labeled by one or more specific "recognition" molecules, to guide growth cones as they establish the different stereotyped innervation patterns. The innervation of the Drosophila embryonic and larval musculature, therefore, is a valuable model system for studying in detail the navigation and target recognition by motoneuronal growth cones of specific identified muscle cells. In this paper we examine the formation of muscle fibers and the pioneering of the peripheral nerves, as well as the temporal aspects of synaptogenesis and the onset of transmitter expression. A detailed analysis of growth cone behavior that results in specific motoneuronal ending anatomy is presented for several muscle fibers. Some of these observations have been published in abstract form (Johansen et al., 1988).

\section{Materials and Mothods}

\section{Preparations and solutions}

Stocks. Wild-type Canton S D. melanogaster stocks were maintained under standard laboratory conditions in uncrowded bottles. Staged and timed embryos were obtained by 1 or $2 \mathrm{hr}$ collections of eggs laid on apple juice-agar plates. The eggs were allowed to develop to the desired stage by incubation at $25 \pm 1^{\circ} \mathrm{C}$. Embryos were staged according to the morphological staging criteria described by Campos-Ortega and Hartenstein (1985).

Saline. Osmotically balanced insect saline solutions consisted of (in mM) $140 \mathrm{NaCl}, 5 \mathrm{KCl}, 5 \mathrm{CaCl}_{2}, 4 \mathrm{NaHCO}_{3}, 1 \mathrm{MgCl}_{2}, 5$ $N$-Tris(hydroxymethyl) methyl-2-aminoethanesulfonic acid (TES), 5 trehalose, and 100 sucrose at $\mathrm{pH} 7.2$. For some of the dissections a 0 
$\mathrm{mm} \mathrm{Ca}, 6 \mathrm{~mm} \mathrm{Mg}$ version of this saline was used to suppress synaptic activity and muscle contractions.

Dissections. Larvae were dissected in Ca-free insect saline by a dorsal incision through the bodywall and pinned out flat in Sylgard coated dishes with $100-\mu \mathrm{m}$ insect pins. All internal organs were removed, exposing the inner surface of the bodywall musculature.

Embryos were manually devitellinized on double-sided tape. For stages prior to the secretion of cuticle (14-15 hr of development) the embryos were attached to clean glass slides and filleted open under insect saline using glass micropipettes. All viscera and yolk were removed. After secretion of cuticle and until hatching (at this stage the embryos do not stick to the glass), the embryos were devitellinized and pinned out in Sylgard coated dishes with the broken tips of glass microelectrodes. To limit muscle contractions the dissections were performed in $\mathrm{Ca}$-free saline which was cooled to $4^{\circ} \mathrm{C}$ by a Peltier plate (Cambion Instruments).

\section{Immunocytochemistry}

Antibody and phalloidin sources. The antiserum to glutamate was the generous gift of Drs. C. Toomim and P. Petrusz. The rabbit antiserum was raised to glutamate coupled by glutaraldehyde to keyhole limpet hemocyanin (Hepler et al., 1986). The antibody has been characterized by Toomim et al. (1986), Hepler et al. (1988), and Johansen et al. (1989). Antiserum to HRP (goat) and a direct fluorescein-conjugated goat HRPantiserum were from Cappel. In addition, rhodamine-conjugated phalloidin (Molecular Probes, Eugene, OR) was used to label actin filaments in muscle fibers.

Fixation and cytochemistry. Preparations were fixed in $4 \%$ paraformaldehyde for $1 / 2-1 \mathrm{hr}$ in $100 \mathrm{mM} \mathrm{NaH}_{2} \mathrm{PO}_{4}$ adjusted to $\mathrm{pH} 7.4$, blocked for $1 \mathrm{hr}$ with $1 \%$ BSA in PBS $\left(20 \mathrm{mM} \mathrm{NaH}_{2} \mathrm{PO}_{4}, 150 \mathrm{mM} \mathrm{NaCl}\right.$, adjusted to $\mathrm{pH} 7.2$ ), and then incubated overnight at room temperature in primary antiserum diluted 1:200-1:400 in TBS (PBS with $0.2 \%$ Triton $\mathrm{X}-100$ ) containing $1 \%$ BSA. Alternatively, staining of filamentous actin was carried out by incubating the tissues overnight in rhodamine-conjugated phalloidin (66 nM) diluted in TBS. After washing in TBS for 1 $\mathrm{hr}$ those preparations requiring secondary labeling were incubated at room temperature for $2 \mathrm{hr}$ in either HRP-, fluorescein- or rhodamineconjugated IgG specific to the primary $(40 \mu \mathrm{g} / \mathrm{ml})$. The HRP reaction was developed as previously described (Johansen et al., 1989). All preparations were rinsed with TBS $(1 \mathrm{hr})$ and distilled water $(15 \mathrm{~min})$ before mounting on slides in 5\% n-propyl gallate glycerol (Giloh and Sedat, 1982).

For double labeling experiments with both glutamate antisera and HRP-specific IgG the preparations were fixed for $1 / 2-1 \mathrm{hr}$ in $4 \%$ paraformaldehyde $/ 0.1 \%$ glutaraldehyde in $100 \mathrm{mM} \mathrm{NaH}_{2} \mathrm{PO}_{4}$, pH 7.4. Following $1 \%$ BSA blocking the preparations were incubated overnight at room temperature in the rabbit-derived glutamate antiserum (1:200$1: 400$ in TBS with $1 \%$ BSA), washed $1 \mathrm{hr}$ in TBS, and then labeled for $2 \mathrm{hr}$ with a sheep-derived antirabbit rhodamine-conjugated $\operatorname{IgG}(40 \mu \mathrm{g} /$ $\mathrm{ml}$ in TBS with $1 \% \mathrm{BSA}$ ). The preparations were washed for $1 \mathrm{hr}$ in TBS before incubation overnight in fluorescein-conjugated goat-derived anti-HRP IgG (25-50 $\mu \mathrm{g} / \mathrm{ml}$ in TBS with $1 \%$ BSA). Tissues were rinsed in TBS and distilled water and mounted as described above.

\section{Digital optical microscopy}

Embryonic Drosophila neurons and growth cones are extremely small, and well-resolved fluorescence micrographs cannot be easily obtained using conventional photographic methods. Effective images of growth cones at high magnification were routinely acquired using computerenhanced digital microscopy. Epi-illuminated fluorescently labeled specimens were observed with a 63X 1.4NA planapochromat objective and $5 \mathrm{X}$ ocular using a Dage-MTI 66 silicon intensifier target (SIT) video camera adjusted for maximal sensitivity and gain. Frames were digitized using an ITI FG100 $1024 \times 1024 \times 12$ bit digitizing board in a 16 $\mathrm{MHz} 386$ desktop computer to yield displayed images of $512 \times 480 \times$ 8 bit resolution. Up to 32 digitized frames were integrated to yield an 8-fold improvement in signal to noise, and the resulting images were processed for gray scale manipulation and inversion. Composite images were made by tableting the in-focus areas of multiple averaged video images taken at different focal planes. Some of the images were convolved with a $7 \times 7$ sharpening algorithm as well as by a median filter. Images were photographed directly from a high-resolution video monitor using Kodak T-MAX 100 or Technical Pan film.

\section{Intracellular dye fills}

Drosophila bodywalls were filleted in $0 \mathrm{mM} \mathrm{Ca}$ saline and secured to glass slides as described in the immunocytochemistry methods. Selected muscle cells were observed using differential interference contrast (Nomarski) microscopy using a $40 \mathrm{X} 0.75 \mathrm{NA}$ water immersion objective with the image relayed via a $5 \mathrm{X}$ ocular to a video camera (Newvicon tube Dage-MTI 70). All intracellular impalements were done by viewing the targeted, image-enhanced cells on a video monitor. $250-400 \mathrm{M} \Omega$ electrodes with tips filled with $10 \%$ Lucifer yellow CS in distilled water were used with shanks backfilled with $1 \mathrm{M} \mathrm{LiCl}$. The dye was iontophoresed into the cells using $0.1-0.2 \mathrm{nA}$ continuous hyperpolarizing current. Dye-filled cells were fixed with $4 \%$ paraformaldchyde or the living dyefilled cells were used for video microscopy as described above. The dyefilled preparations were processed for anti-HRP staining, to establish precisely the stage of development and correlate the muscle fiber differentiation to neurite outgrowth.

\section{Results}

Muscle pattern, peripheral nerves, and stereotyped neuromuscular innervation in larvae

The musculature of each hemisegment in the bodywall of mature embryos and larvae is organized into a segmentally repeated pattern of 31 or fewer discrete unicellular muscle fibers. While there are segment-specific patterns for each of the thoracic segments T1-T3, and the most posterior abdominal segment A8/ 9 , the same pattern is used in abdominal segments A1-A7, with the exception of a single fiber difference in A1 (Campos-Ortega and Hartenstein, 1985; Anderson et al., 1988). In the following all descriptions are derived from observations of the abdominal segments A1-A7. The left panel of Figure 1 shows the pattern of a single abdominal hemisegment with the filamentous actin of the muscle fibers fluorescently labeled with rhodamine-conjugated phalloidin. Each muscle fiber is clearly distinguishable and singly identifiable on the basis of its position, size, and orientation. The numbering system used to name the muscle fibers (middle panel of Fig. 1) is adapted from Crossley (1978) and Anderson et al. (1988). It shouid be noted that rare variations in the basic pattern can be encountered; for example, occasionally one of the dorsal external longitudinal fibers $(9,10$, or 11) in a single segment may be missing, as is illustrated in Figure 1.

The bodywall musculature is innervated by central motoneurons, which extend their axons through 2 peripheral nerve roots, the anteriorly positioned intersegmental nerve (ISN) and the posteriorly positioned segmental nerve (SN) (Thomas et al., 1984; Canal and Ferrus, 1986). The segmental nerve can further be divided into four major branches, which are denoted in this paper as $\mathrm{SNa}, \mathrm{b}, \mathrm{c}$, and d. In Figure 1 (right panel) the trajectory of the peripheral nerves is illustrated, indicating as well the specific muscle fibers innervated by each of the nerve branches. The dorsal musculature is innervated by the ISN, whereas the ventral muscle fibers are innervated exclusively by the $\mathrm{SN}$. This analysis is based on tracings of peripheral nerves labeled with anti-HRP antiserum (aHRP) in bodywall preparations of third instar larvae. The antibodies are specific to the membrane surfaces of all insect neurons (Jan and Jan, 1982; Snow et al., 1987). In addition to innervating the bodywall musculature, the two nerves collect axons from the different groups of peripheral sensory neurons (Campos-Ortega and Hartenstein, 1985; Canal and Ferrus, 1986; Ghysen et al., 1986; Hartenstein, 1988), and thus they contain both afferent and efferent axons.

Using a glutamate-specific antiserum we recently demonstrated that glutamate-immunoreactive motoneurons innervate the entire larval bodywall musculature, with each muscle fiber re- 

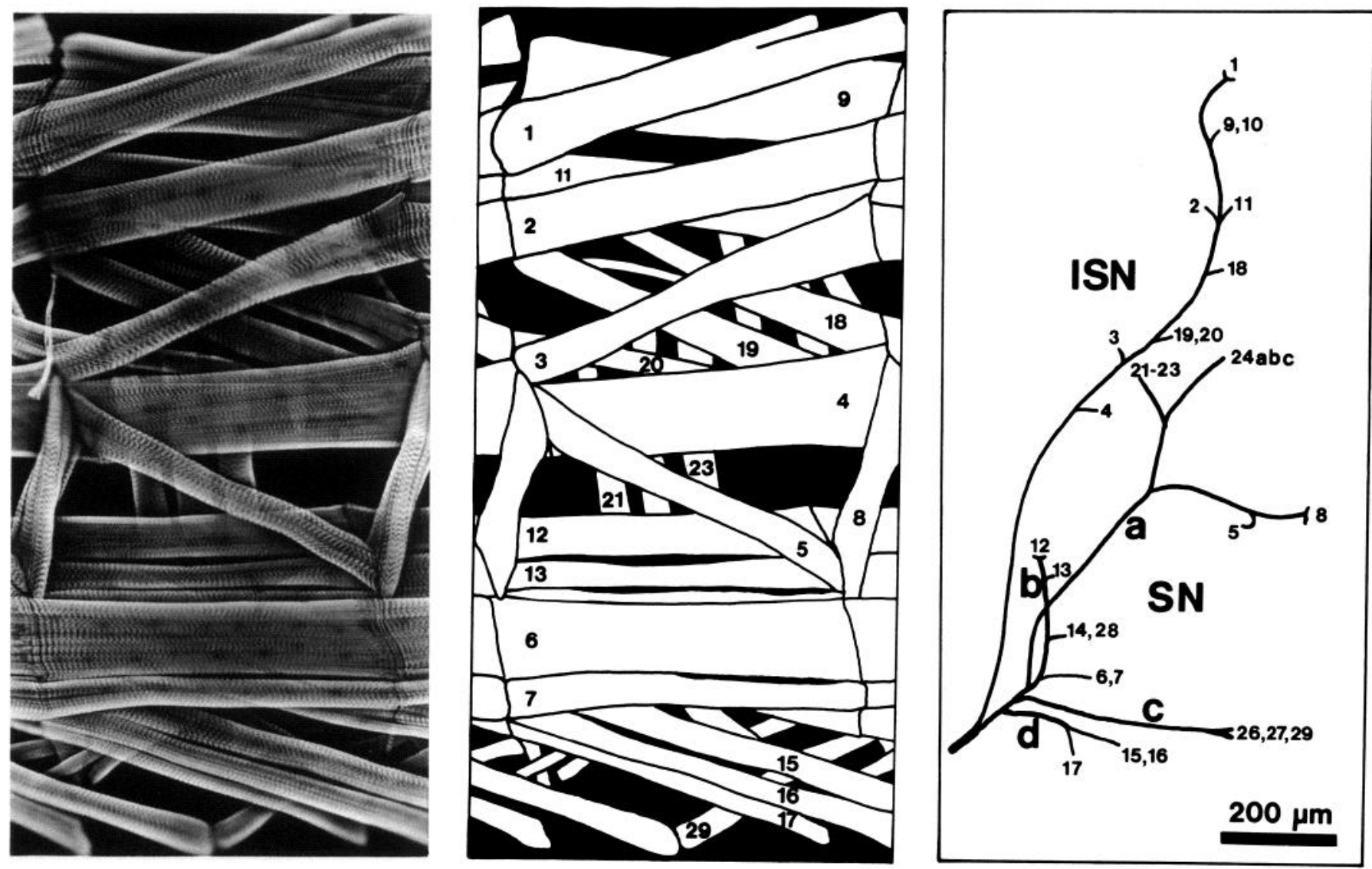

Figure 1. The abdominal segmental muscle fiber pattern and its innervation by the 2 peripheral nerve roots. In this and all following figures anterior is to the left and dorsal at the top. Left panel, Muscle fibers of an abdominal hemisegment labeled by rhodamine-conjugated phalloidin. Middle panel, A schematic representation of the muscle fibers in the left panel, with the fibers illustrated given their identifying numbers. Right panel, Schematic drawing of the intersegmental nerve $(I S N)$ and the segmental nerve $(S N)$ based on tracings of the nerves labeled with HRP-specific antibodies. The $\mathrm{SN}$ has been subdivided into 4 branches $(a, b, c$, and $d)$. The numbers identify the muscle fibers innervated by the various branches of the nerves.

ceiving at least one glutamatergic ending (Johansen et al., 1989). The motoneuronal innervation is initiated at a stereotyped location for each muscle fiber, from which moderately branched varicose nerve processes project over the internally facing muscle surface. Endings on individual muscle fibers have distinct and stereotyped branching patterns, with the motoneuronal processes occupying characteristic surface domains of the muscle fiber.

In this study anti-HRP immunocytochemistry was used to label developing embryonic neurons, to reveal all participating efferent and afferent projections. The aHRP allowed us to describe the morphology of neuronal projections prior to the onset of transmitter expression. We have compared neuromuscular junctions in larvae labeled with the glutamate-specific antiserum to those labeled with the anti-HRP antibodies, to determine whether the glutamatergic projections represent all or only a subset of the innervating axons. Figure 2 illustrates the HRPantiserum labeling of third instar muscle fibers 4,12 , and 13 , and 6 and 7. The morphology of these motoneuronal endings was indistinguishable from that obtained with the glutamate antiserum (aGlu; cf. to figures 3 and 4 from Johansen et al., 1989). A direct correlation is shown in Figure 3, comparing the same neuromuscular projections on muscle fibers 12 and 13 (Fig. 3, $A, B$ ) and 4 (Fig. 3, $C, D$ ) double labeled with both the aGlu and the aHRP. The labeling by the 2 probes is coextensive for each of the neuromuscular endings on the 3 muscle fibers illustrated. Similar results obtained for muscle fibers 2, 4, 6, 7, 12 , and 13 throughout the bodywall strongly indicate that all nerve endings innervating skeletal muscle fibers in Drosophila larvae are glutamatergic. The anti-HRP-labeled junctions therefore confirm the earlier description of muscle fiber-specific and anatomically stereotyped neuromuscular junctions that were obtained using transmitter specific probes. The remainder of this paper describes how the stereotypic innervation pattern observed in larvae is established during embryogenesis through a series of highly orchestrated and precisely timed events.

\section{Muscle formation}

As the axonogenesis and initial outgrowth of pioneering axons from the CNS takes place in embryos before muscle fibers have formed (Campos-Ortega and Hartenstein, 1985), the temporal relationship between muscle differentiation and peripheral nerve development was examined to follow possible interactions between the events. The anterior corner cell $(\mathrm{aCC})$ is the first motoneuron to extend an axon toward the periphery and this neuron is thought to pioneer the ISN at the beginning of stage $13(9.30-10.00 \mathrm{hr}$ postfertilization; Thomas et al., 1984; Canal and Ferrus, 1986). At this stage the somatopleura, which gives rise to the somatic musculature (Campos-Ortega and Hartenstein, 1985), consists of a layer of unfused spheroidal mesoder- 
mal cells without any obvious signs of organization within the segment (Fig. 4A). By stage 14, however, the mesodermal cells of the somatopleura have begun to aggregate and fuse to become the syncytial muscle fibers (Fig. $4 B$ ). Several identifiable muscle fibers, principally the internal and external longitudinals, can be distinguished at this stage. In Figure $4 B$ the white arrows indicate the developing ventral longitudinal muscle fibers $(6,7$, 12 , and 13). Throughout stage 14 fusion continues between the developing muscle fibers and the numerous myoblasts present at the bodywall (Fig. $4 B$, black arrows).

In contrast to the grasshopper embryo, where muscle pioneers are responsible for structuring the muscle pattern (Ho et al., 1983; Ball et al., 1985a), it is not known in Drosophila how the correct muscle fiber pattern is being organized, or how fibers insert on the epidermis at the proper sites. Intracellular Lucifer yellow dye fills of mesodermal cells in the somatopleura during early stage 13 revealed that most of the mesodermal cells were small and round without any distinguishing features; however, among these cells a few larger, segmentally repeated bipolar cells were identified ( $n=6$ examples observed; Fig. $5 \mathrm{~A}$ ). These cells are good candidates for being the muscle pioneers of Drosophila embryos. They are located on the inner surface of the ectoderm and extend large growth cones toward the anterior and posterior segmental borders (Fig. 5A, arrows). These projections appear to delineate the future muscle fiber insertion sites. Thus, the Drosophila cells share several properties with the grasshopper muscle pioneers previously described, including a bipolar shape, growth cone-like processes at each end, and their early appearance among the developing myoblasts (Ho et al., 1983; Ball et al., 1985a). Time-lapse video analysis will be required to determine whether these bipolar cells in Drosophila embryos undergo fusion with the myoblasts and thus develop into muscle fibers, or alternatively serve as substrates for myoblast alignment.

Lucifer yellow dye fills of muscle fibers also revealed that several of the longitudinal muscle fibers are transiently dyecoupled during stages $14-15$ ( $n=4$ embryos; Fig. $5 B)$. The coupling was observed in up to 4 adjacent fibers. However, by late stage 15 this dye coupling is lost (Fig. 5C), and each muscle fiber appears to be a separate and independent entity for the rest of development.

We did not detect either dorsoventral or rostrocaudal timing gradients in the development of the muscle fibers. As shown in Figure $4 C$, the muscle fiber pattern is essentially complete by late stage 15 , although a few individual unfused myoblasts are still present (Fig. 4C). At this stage of development (which approximately coincides with dorsal closure) spontaneous contractions of the musculature begin. This is correlated with the onset of phalloidin staining in the individual muscle fibers, indicating the presence of filamentous actin in the sarcomere (Fig. 6). Thus, the development of a fully organized pattern of contracting muscle fibers from an initial mass of spheroidal myoblasts is accomplished within $2 \mathrm{hr}$.

\section{Pioneering and formation of the peripheral nerves}

When the first central axons pioneer the ISN at early stage 13 they do it in an environment of as yet unfused myoblasts, an expanse that is seemingly devoid of organization except for the putative muscle pioneers. While there are no obvious morphological guidance cues at the light microscopic level evident in the organization of the developing myoblasts, the first peripheral sensory neurons are appearing in the epidermis at the same time
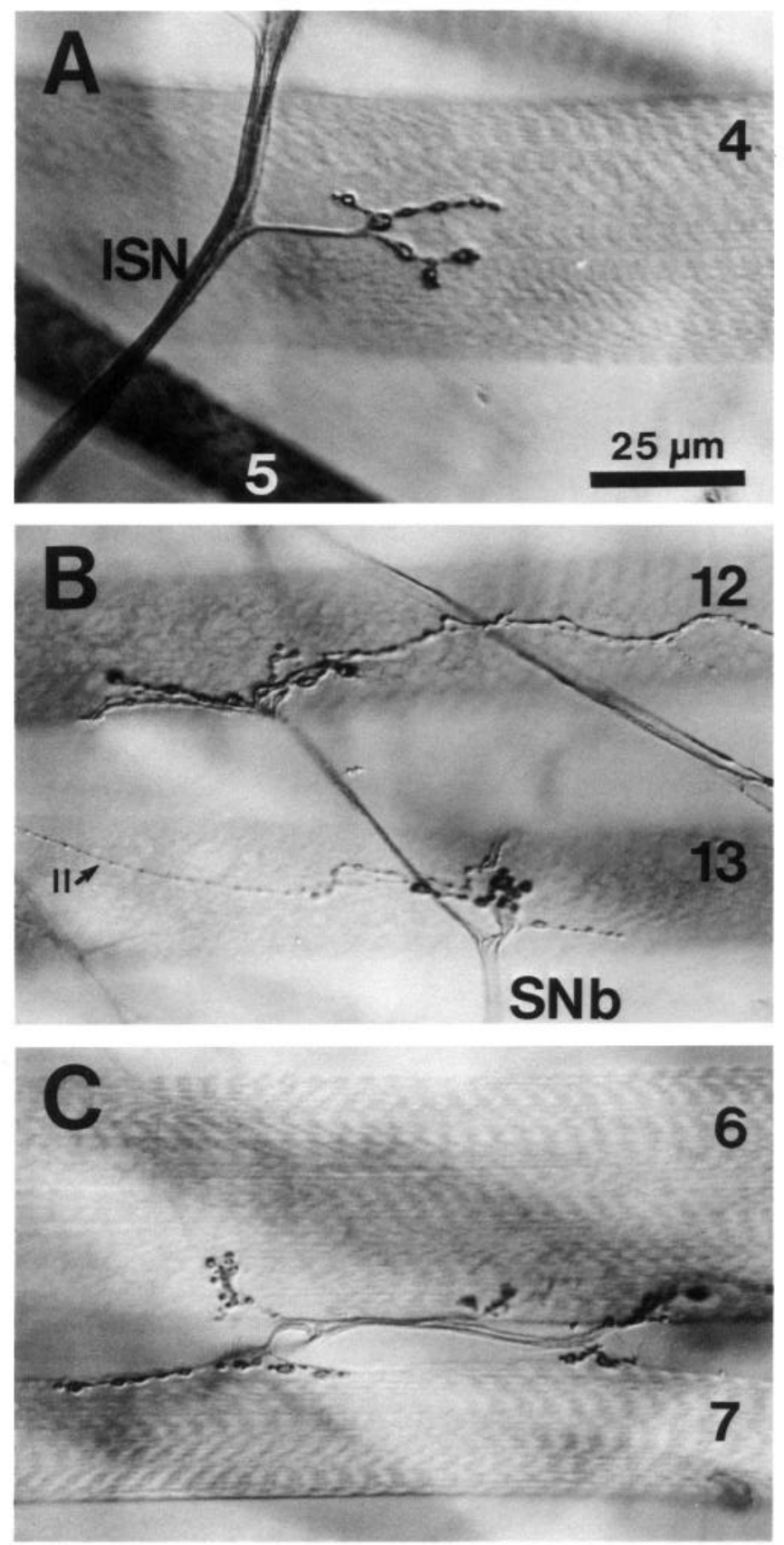

Figure 2. The characteristic muscle fiber-specific anatomy of neuromuscular junctions labeled with HRP-specific antibodies. $A$, The typical short Type I nerve ending on muscle fiber 4, which branches off the ISN. $B$, Motor endings on muscle fibers 12 and 13 , which are innervated by the segmental nerve branch b $(S N b)$. $C$, Nerve endings on muscle fibers 6 and 7, showing labeled projections running longitudinally along the cleft between the fibers. Peroxidase immunocytochemistry. II, Type II varicose endings of less than $2 \mu \mathrm{m}$.

that the efferents begin their outgrowth. The several classes of sensory neurons are generated in a dorsoventral sequence, starting with the dh1 (dorsal hair 1) sensory neuron (Ghysen et al., 1986; Hartenstein, 1988). The axons of these peripheral sensory neurons project toward the CNS at the same time the efferent axons grow toward the dorsal midline. Efferent and afferent pioneer axons meet and fasciculate in early stage 14 embryos 

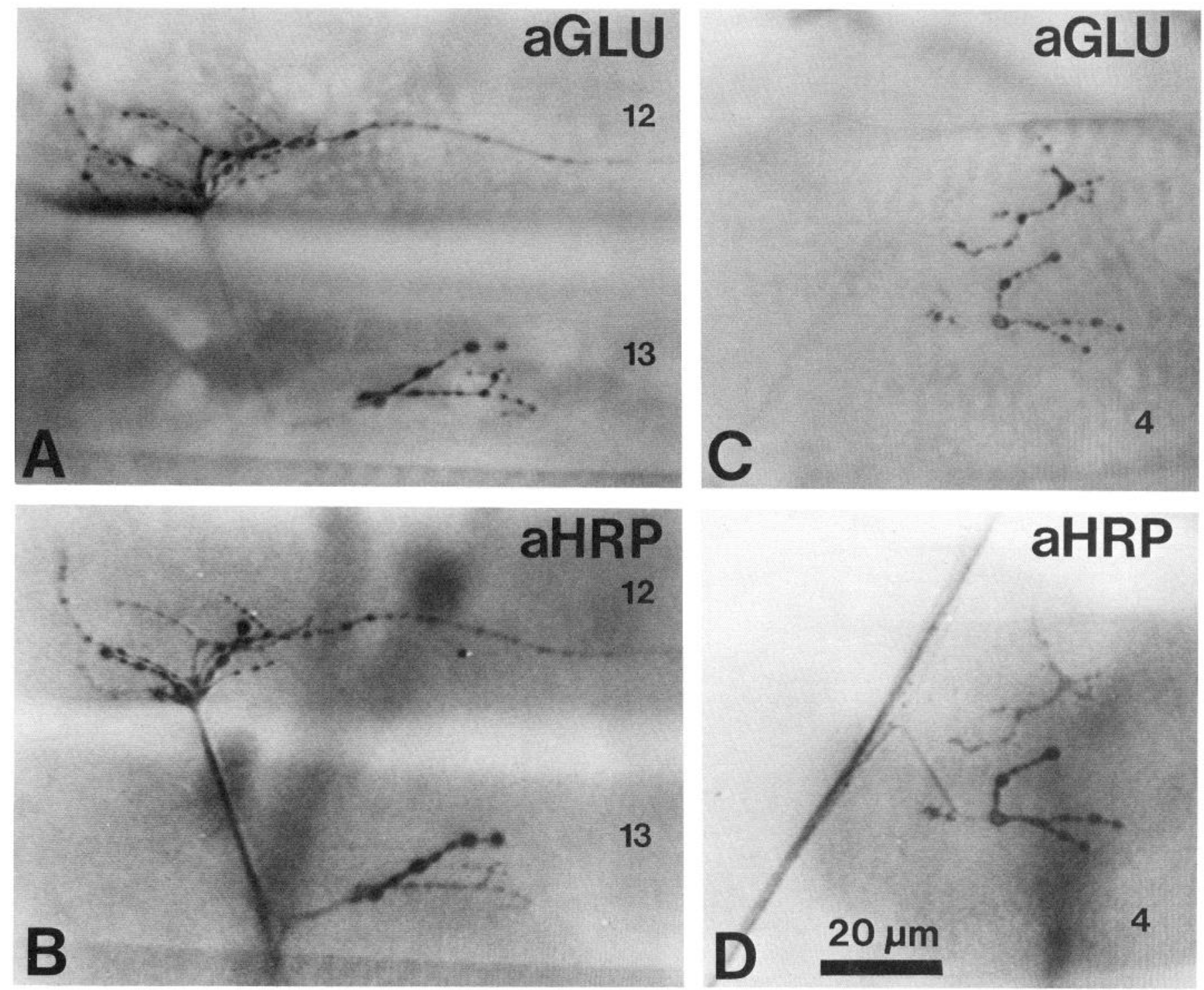

Figure 3. Double labeling of nerve endings with HRP and glutamate-specific immunocytochemistry. $A$, Motor endings on muscle fibers 12 and 13 labeled with glutamate antiserum $(a G L U)$ and rhodamine-conjugated secondary antibody. $B$, The same endings as in $A$ labeled with fluoresceinconjugated anti-HRP antiserum $(a H R P)$. $C$, Nerve endings on muscle fiber 4 labeled with glutamate antiserum and rhodamine-conjugated second antibody. $D$, The same endings as in $C$ labeled with fluorescein-conjugated anti-HRP. In both cases the labeling by the HRP and glutamate antisera is coextensive.

at a site approximately halfway between the dorsal and ventral midline (Ghysen et al., 1986; Hartenstein, 1988). It is possible that the sensory cells or their axons play a role in the distal guidance of the ISN efferents to their muscle fiber targets, although no experimental evidence has been presented supporting this notion. The initial outgrowth of aCC and the follower $\mathrm{U}$ neurons from the CNS (Thomas et al., 1984) is dependent first on the recognition of specific glial cells, including the segmental boundary cell (SBC; in grasshoppers: Bastiani and Goodman, 1986; in Drosophila: Jacobs and Goodman, 1988). Once out of the CNS the axons project through the mass of myoblasts in the ventral somatopleura which will later form the ventral internal longitudinal muscle fibers $(6,7,12$, and 13). Distal to this point the axons project away from the ectoderm toward the embryonic interior and subsequently grow over the inner facing surfaces of the developing myoblasts (Fig. 7, $C, D$ ). Initially the growth cones follow a trajectory close to the anterior border of the segment. In the mid-bodywall region the growth cones angle their trajectory posteriorly and then continue their distal trajectory halfway between the anterior and posterior segmental borders (Fig. 7, $C, E$ ). This sequence of axonal projections is illustrated in Figure 7, where HRP-antibody-labeled bodywall preparations from stages 14-16 are shown with corresponding Nomarski images indicating the state of muscle development.

Figure $7 A$ shows the efferent pioneer axons of the ISN at stage 14 when they meet and fasciculate with the first dorsal sensory afferent axons. While afferent axons contact and follow the ISN axons proximally into the CNS, the distally directed ISN growth cones pioneer an independent trajectory toward the dorsal midline without following any obvious structural guidance cues or other axons. At this stage the somatopleura is still in a dynamic state of muscle formation, with only a few of the muscle fibers 
yet visible (Fig. $7 B$ ). The first axons pioneering the $\mathrm{SN}$ are emerging from the CNS at this time.

By stage 15 (Fig. 7C) the ISN is more robustly labeled by the HRP antibodies than at stage 14 (Fig. $7 \mathrm{~A}$ ), owing to the addition of both afferent and efferent axons to the nerve. Peripheral neurogenesis is now nearly complete. The full trajectory of the ISN can be traced from the CNS to near the dorsal midline. Many of the filopodia of the ISN axonal growth cones are clearly visible (Fig. $7 C$, curved arrow). The full extent of the filopodia reach $15 \mu \mathrm{m}$ and are able to sample the entire width of each segment. At this stage growth cones pioneering the $\mathrm{SN}$ are prominent some $2 \mathrm{hr}$ after their ISN counterparts (Fig. $7 \mathrm{C}$ ).

By stage 16 the ISN has reached the dorsal midline (Fig. $7 E$ ) and spaced growth cones are clearly visible along the ISN at the branch point sites where axons will diverge to innervate particular muscle fibers. The several branches of the $\mathrm{SN}$ are also being pioneered at this time, as illustrated in Figure $7 E$. Figure 8 demonstrates the relationship between the ISN and the emerging $\mathrm{SNa}$ and $\mathrm{c}$ branches, and shows the lateral and ventral sensory neurons that project into the $\mathrm{CNS}$ through the $\mathrm{SNa}$ and c branches. The growth cones of the $\mathrm{SNa}$ subbranch, which will innervate muscle fibers $21-24$, are indicated by the arrow. The arrowhead points to the growth cones of the small branch which projects posteriorly within the mid-segment to innervate muscle fibers 5 and 8 . The $\mathrm{SNa}$ is the first branch of SN to appear and precedes the $\mathrm{SNb}, \mathrm{c}$, and $\mathrm{d}$ branches, which emerge simultaneously.

As a rule axons innervating the most distant peripheral targets are the first to exit the CNS, while axons innervating more closely located targets exit later, following an order inverse to the distance they will grow. Thus, the anterior nerve ISN, which innervates the dorsal musculature, is the first nerve to be pioneered. By the time the ISN growth cones reach the dorsal midline the pioneering axons of the SN have exited the CNS; they will subsequently pioneer branch $\mathrm{SNa}$. These axons will also innervate the most distant targets (muscle 5, 8, 21-24) of the nerve. The axons of $\mathrm{SNb}, \mathrm{c}$, and $\mathrm{d}$, which innervate more proximal muscle fibers roughly equidistant from the CNS, appear simultaneously a short time later. The dorsal muscle fibers, which have not yet been formed when the first axons of the ISN exit the CNS, are differentiated by the time ISN collateral growth cones reach them. By contrast, the $\mathrm{SN}$ axons, which have a much shorter distance to grow, exit the CNS at a later stage and thus reach their targets at approximately the same time the ISN axons do. The coordinated outgrowth of axons from the CNS in each segment compensates for the time it takes to reach peripheral targets, and as a result ensures that the onset of synaptogenesis is synchronous throughout the segment. As there are no major timing gradients in neuromuscular development between the segments, the skeletal muscle fibers through the bodywall are innervated in a synchronous fashion during stage 16. This is borne out by the corresponding synchronous onset of transmitter expression at neuromuscular endings (see below).

\section{Pioneering of branch $\mathrm{SNb}$ and the formation of neuromuscular junctions}

To examine the muscle fiber-specific cues used to guide growth cones to their targets, we focused on the pioneering of the $\mathrm{SNb}$ projection. This branch of the segmental nerve projects almost exclusively on the surfaces of muscle fibers, and hence its description is not complicated by the presence of fasciculating afferent axons, as are the other nerve branches. Furthermore, as the $\mathrm{SNb}$ trajectory runs for part of its length on the internally
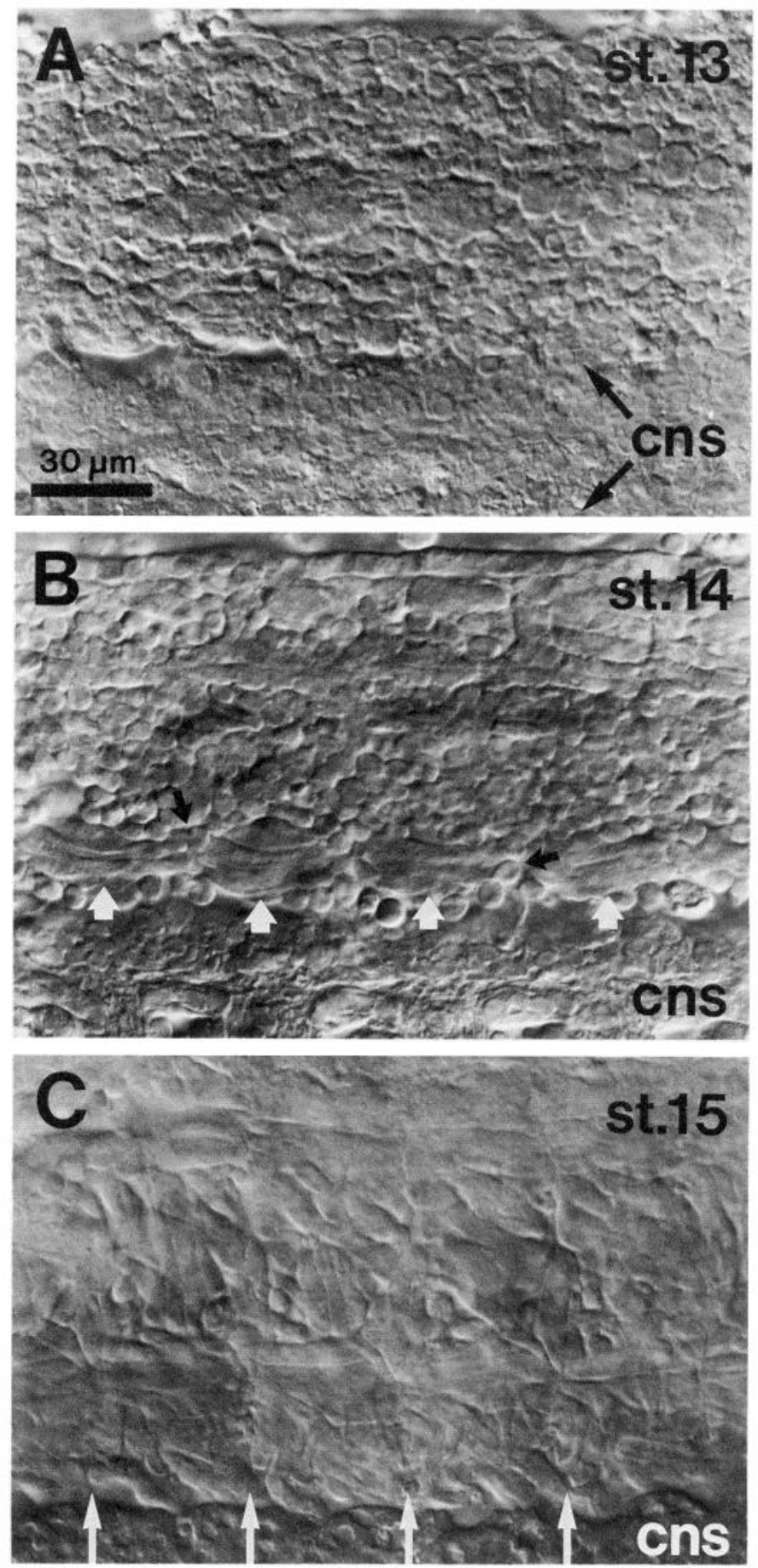

Figure 4. Muscle development in Drosophila embryos. In each of these fillets 5 ipsilateral abdominal segments are shown at 3 successive stages. The segmental borders of the 3 figures are similarly aligned and are indicated by the white arrows in $C$. $A$, Stage 13 embryonic fillet. The CNS is indicated by the arrows. The mesoderm, viewed here from its internal aspect, consists of undifferentiated myoblasts with little apparent organization. $B$, Stage 14. Many of the muscle fibers are beginning to be recognizable (the small white arrows here indicate the ventral longitudinal muscle fibers). Numerous small round myoblasts are still present (black arrows), some of which appear to be fusing to form the muscle fibers. $C$, Stage 15 . The final pattern of muscle fibers has been formed and individual muscle fibers are now distinctly recognizable. The white arrows indicate the segmental borders. Compare with Figure 6 for the rhodamine phalloidin staining of the muscle fibers at this stage of development. 

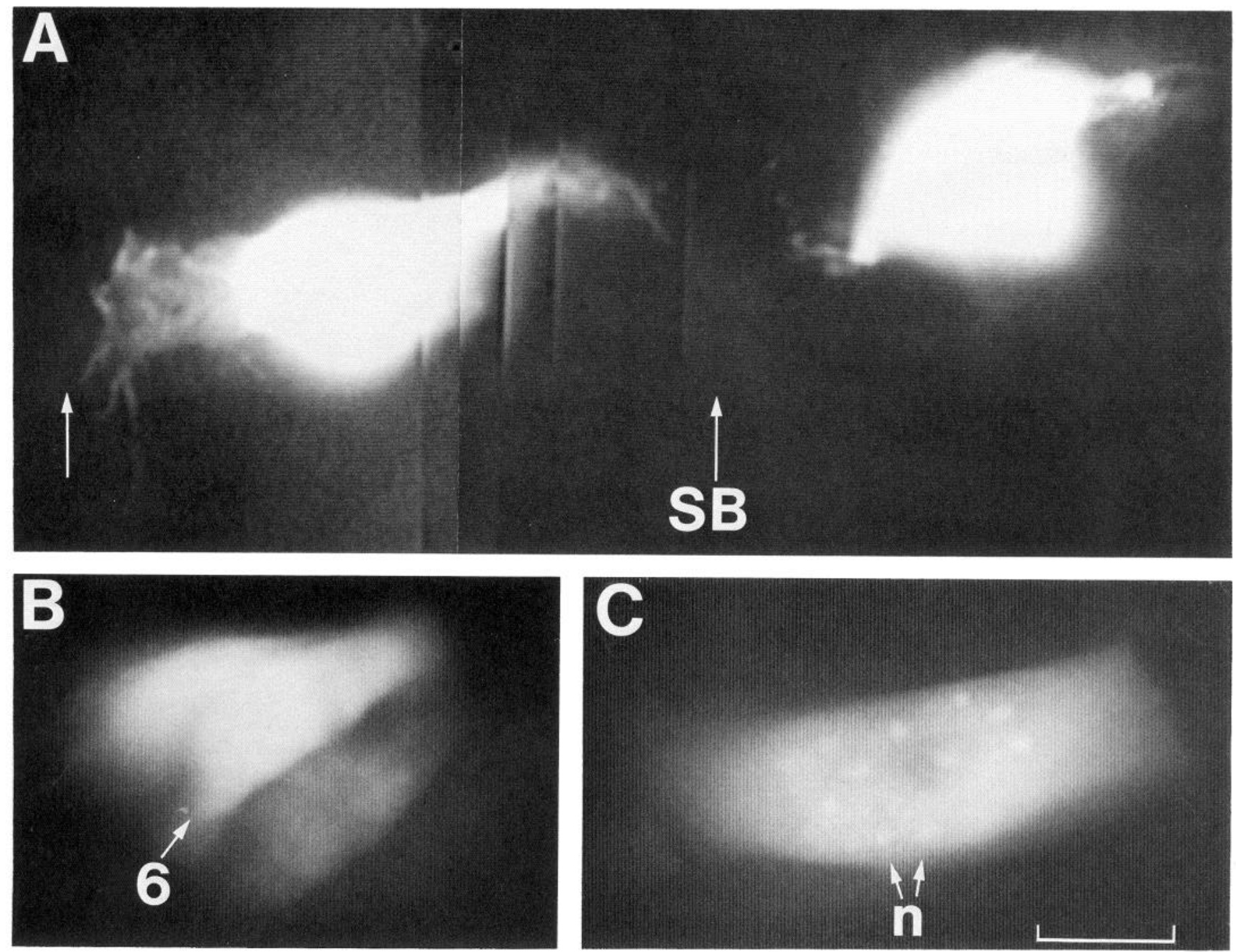

Figure 5. Lucifer yellow dye fills of developing muscle fibers and putative muscle pioneers. A, Homologous presumptive muscle pioneers and their extensive filopodial processes, revealed in 2 adjacent abdominal segments by intracellular Lucifer yellow dye fills of a stage 13 embryonic fillet. The segmental borders $(S B)$ are indicated by arrows. B. The internal longitudinal muscle fiber 6 was impaled and dye-filled in a stage 14 embryonic fillet. After several minutes Lucifer yellow could be seen in muscle fiber 7, and a short time later in muscle fibers 12 and 13 . The dye coupling was restricted to the segment. $C$, By late stage 15 dye filling indicates that muscle fibers are uncoupled. Here a single internal dorsolateral longitudinal muscle fiber 4 was filled. The muscle nuclei are clearly revealed $(n)$. The video fluorescence images are from living, unfixed preparations from 5 to $10 \mathrm{~min}$ after impalement. Scale bars $A, C, 5 \mu \mathrm{m} ; B, 10 \mu \mathrm{m}$.

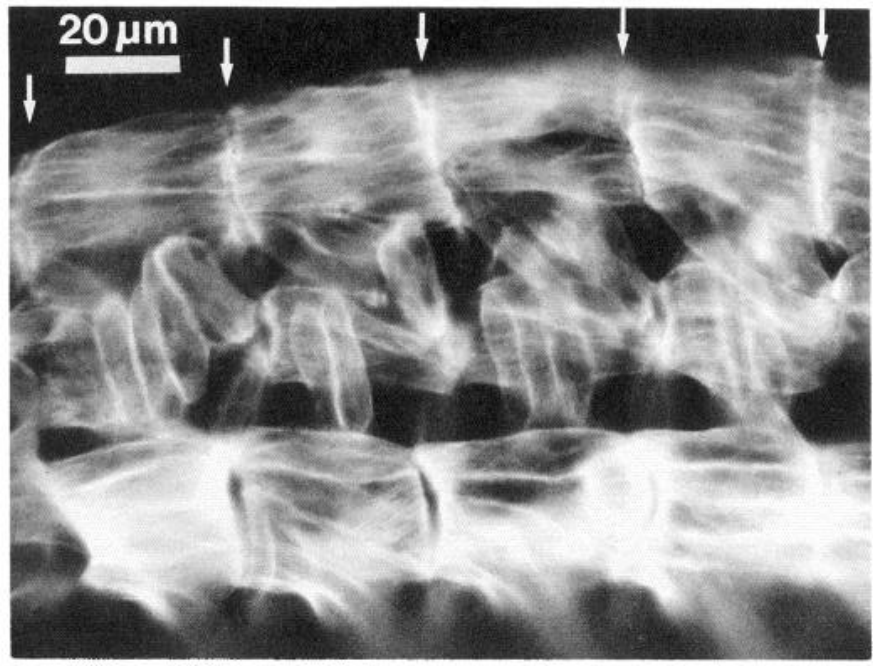

facing surfaces of the musculature, the axons are physically separated from potential surface guidance cues located on the epidermis. The $\mathrm{SNb}$ innervates only 6 muscle fibers (Fig. 1) and at its distal extent terminates on muscle fiber 12 .

Figure $9 A$ shows the growth cones pioneering the $\mathrm{SNb}$ branch emerging from the CNS in a late stage 15 embryo. In contrast to the ISN, the pioneering neurons for this nerve branch are not yet identified. At this stage the muscle pattern is fully formed, providing a different environment when compared to the mesodermal layer of undifferentiated myoblasts through which the

Figure 6. Fillet of stage 15 embryo labeled with rhodamine-conjugated phalloidin. The individual muscle cells in the final segmental pattern are clearly recognizable. Phalloidin binding filamentous actin is visible within the muscle fibers at this stage. Arrows point to the segmental borders. 

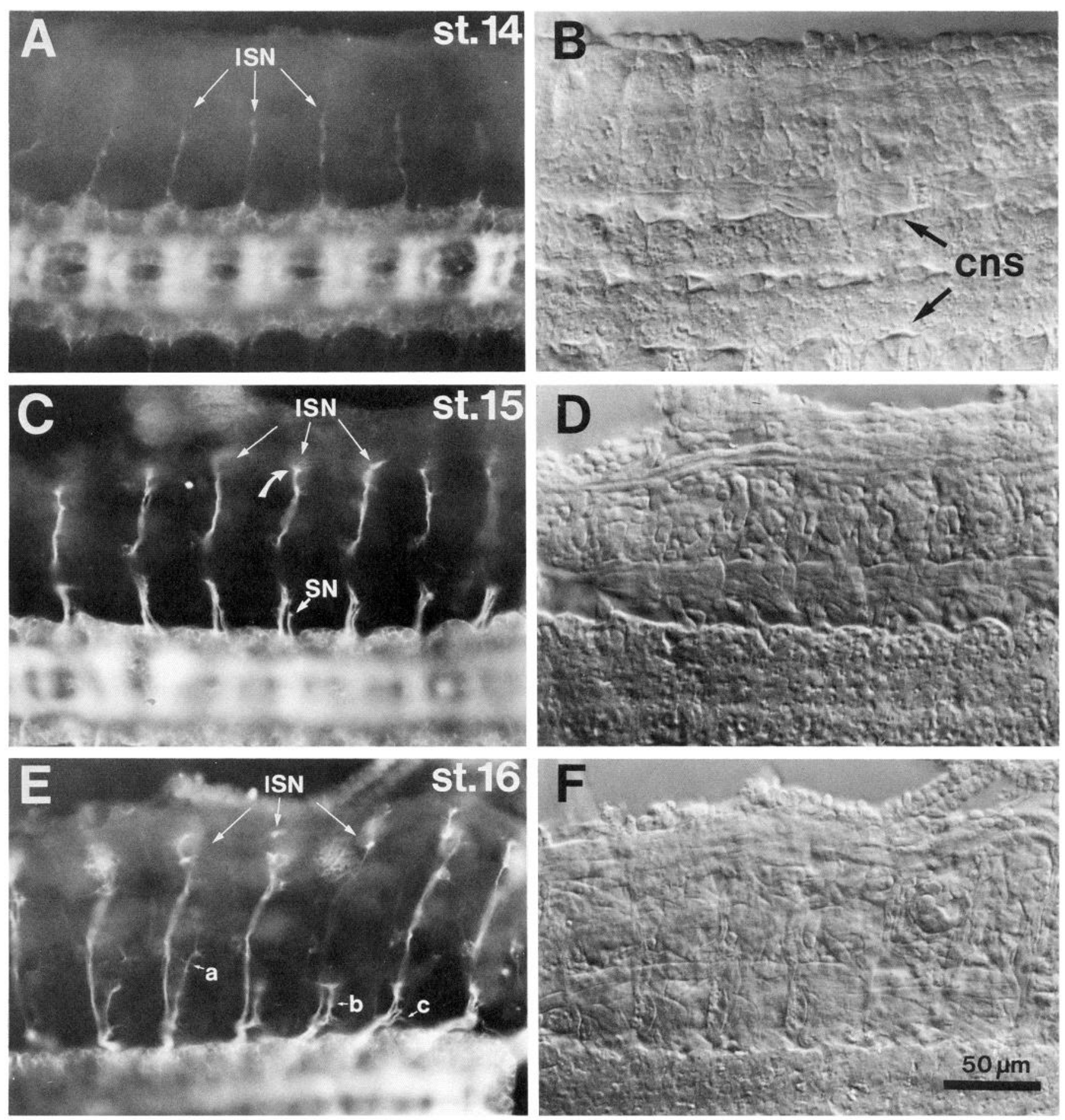

Figure 7. The development of the intersegmental $(I S N)$ and segmental nerves $(S N)$, viewed in embryonic fillets. $A$, Early outgrowth of the ISN during stage 14. $B$, Nomarski image of $A$. $C$, The ISN at stage 15. The curved arrow points to the pioneering growth cones at the advancing tip of the nerve (note the apparent gap in the staining where for a short stretch the $I S N$ grows beneath the ventral internal longitudinal muscles and is out of focus). The growth cones of the $S N$ (arrow) have exited the CNS. $D$, Nomarski image of $C$. $E$, At stage 16 the ISN has reached the dorsal midline and the trajectories of the subbranches of the $S N(a, b$, and $c)$ are in the process of being pioneered. $F$, Nomarski image of $E$. Most of the peripheral neurons are out of the plane of focus in these images. The nerves were labeled with HRP antibody and visualized with fluoresceinconjugated secondary.

ISN grew. The growth cones of the SNb begin their projection wedged between the internally facing surfaces of muscle fibers 14 and 28 and the externally facing surface of muscle fibers 6 and 7. By early stage 16 the growth cones have reached the border between muscle fibers 6 and 13 (Fig. 9, B, C). Here the growth cones flatten and extend filopodia along the lateral edge of muscle 13, displaying a characteristic T-like appearance (Fig. $9, B, C)$. Elsewhere along the length of the $\mathrm{SNb}$ other growth cones emerge to project over muscle fibers 6 and 7 and 14 and 28 , as illustrated in the tracing on the Nomarski image in Figure 


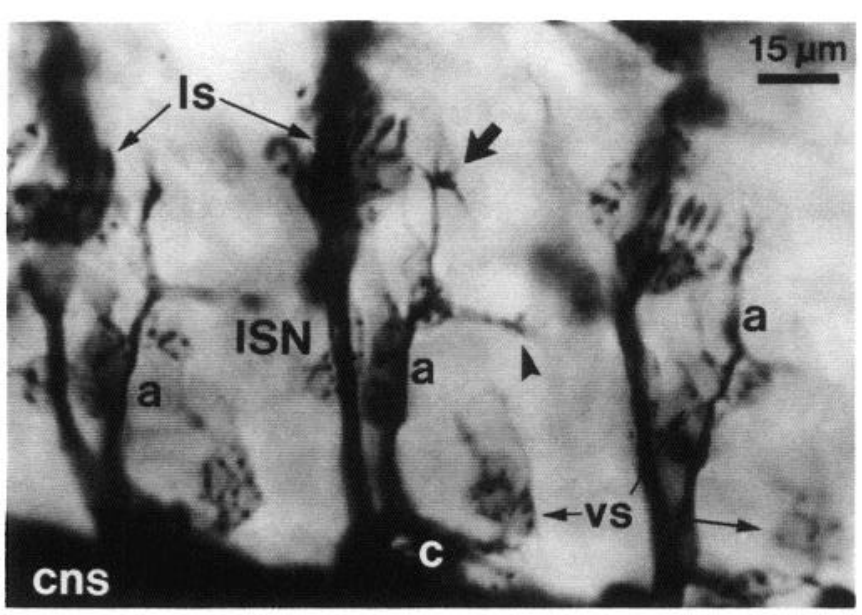

Figure 8. Growth cones of the $\mathrm{SNa}$ branch in a stage 16 embryo. The figure shows the stereotyped trajectories of the $\mathrm{SNa}$ in three adjacent segments. The arrowhead indicates growth cones from the $\mathrm{SNa}$ subbranch that will innervate muscle fibers 5 and 8 , whereas the arrow points to growth cones of axons that will innervate muscles 21-24. The preparation was labeled by HRP antibody and fluorescein-conjugated secondary. $l s$, lateral sensory neurons; $v s$, ventral sensory neurons.

$9 D$. The growth cones of the axons innervating muscle fibers 6 and 7 extend along the cleft between the two muscle fibers where they are apposed to each other (Fig. 9, D, F).

Immediately following the exploration of the lateral edge of muscle fiber 13 a growth cone emerges from the T (Fig. 9, E, $F$, arrows) which navigates across the inner surface of muscle 13 and projects to a specific, stereotyped site on the anterolateral membrane surface of muscle fiber 12 . While the growth cone at this stage has filopodia long enough to sample the entire surface of muscle 12 , it invariably contacts the muscle fiber at a specific site that is located on the anterior-medial internally facing surface of the cell. There are no distinguishing morphological features on the muscle fiber surface visible in the light microscope that characterize this site, nor does it correspond to the location of one of the fiber's nuclei. The precise selection of this one region of the fiber strongly suggests the presence there of a localized guidance cue residing on the muscle fiber membrane surface itself.

By the middle of stage 16 glutamate immunoreactivity appears in the axonal endings (Fig. 10). Our present experiments do not allow us to determine whether the glutamate expression slightly precedes innervation or whether it coincides with the establishment of neuromuscular junctions. However, if the embryo is released from the egg at this stage, it will show bending and flexing and other forms of coordinated movements, strongly suggesting that the neuromuscular junctions have become functional.

A major focus of our work was to determine how the stereotyped morphology of the neuromuscular innervation of particular muscle fibers is formed during development. Figure 11 shows the progressive elaboration of the neuromuscular innervation of muscle fibers 12 and 13, and 6 and 7. The first neuromuscular contacts are highly localized and resemble growth cones, consisting of 1-3- $\mu \mathrm{m}$ swellings of the process, from which fine filopodia extend over the inner facing muscle fiber surface (Figs. $10 ; 11, A, B$ ). The primary contact in the embryo is made at precisely the same area of the muscle fiber surface which will correspond to the nerve entry point in third instar larvae. Furthermore, the trajectory and branch morphology of the initial neuromuscular contact establishes de novo the basic elements of the mature branch anatomy of the junctions. For example, Figure $11 \mathrm{~A}$ shows that the distinct branch and ending features of muscle fibers 12 and 13 are evident in the first contacts made on the fibers in the embryo: here muscle fiber 12 has its characteristic $\mathrm{Y}$-shaped anteriorly and posteriorly directed nerve processes while muscle fiber 13 has its typical posteriorly directed process. Muscle fibers 6 and 7 also have their characteristic neuromuscular projection confined to a narrow, 1- $\mu \mathrm{m}$ strip along each fiber where they are apposed. At stage 17 the morphology is maintained, with the length of the neuromuscular endings increased together with the size of the muscle fibers (Fig. 11, C, D). During the remainder of stage 17 through hatching the neuromuscular junctions expand over the muscle fiber surface and the thinner Type II endings appear. The postembryonic innervation pattern in the first instar larvae (Fig. 11, E, $F$ ) very closely resembles that of third instar larvae (Fig. 2).

The sequence of events described in detail for muscle fibers 6 and 7, and 12 and 13 also holds true for the other segmental muscle fibers. Thus, (1) After the growth cones from the innervating axons reach their target muscle fibers they initiate contacts at specific and stereotyped membrane sites. (2) The earliest contacts consist of 1 or $21-3-\mu \mathrm{m}$ growth cone-like swellings from which fine filopodia extend over the inner muscle surface. (3) Expression of the neurotransmitter glutamate appears just prior to or coincidental with the establishment of the first neuromuscular contacts. (4) The characteristic mature neuromuscular junction branching pattern for each muscle fiber is apparent in the morphology of the initial innervation.

\section{Discussion}

In this paper we have examined the formation of bodywall muscle fibers and the development of their anatomically stereotyped innervation by the efferent motoneuronal axons in Drosophila embryos. We find that these events occur in a precisely timed, essentially invariant sequence. Figure 12 gives a schematic summary of the relative development of the bodywall muscle fibers, the CNS, and the peripheral nerves. This is shown in relation to staging features during embryogenesis, from completion of germband shortening to hatching (Fig. 12).

\section{The pioneering of peripheral nerves}

An important observation emerging from this analysis is that the bodywall muscles differentiate synchronously throughout the segments and that the mature pattern of muscle fibers is fully formed before synaptic innervation takes place. Furthermore, the 2 peripheral nerve branches innervating the bodywall musculature are pioneered in a sequential fashion. Thus, the axons of the ISN, which exclusively innervate dorsal and dorsolateral muscle fibers, are the first to grow out, at a time when the bodywall substrate consists of undifferentiated myoblasts. In contrast, the $\mathrm{SN}$, which innervates only ventral muscle fibers, exits the CNS $2 \mathrm{hr}$ later when the muscle fibers have fully formed. While we have not been able to correlate specific growth cones to CNS cell bodies in this study, there are probably in each segment at least 2 distinct populations of motoneurons, whose timetable of differentiation is staggered by about $2-3 \mathrm{hr}$, and whose axons exit the ISN and SN, respectively. However, because the ISN has to reach the dorsal muscle fibers and thus has a further distance to grow than the $\mathrm{SN}$, it reaches its target 

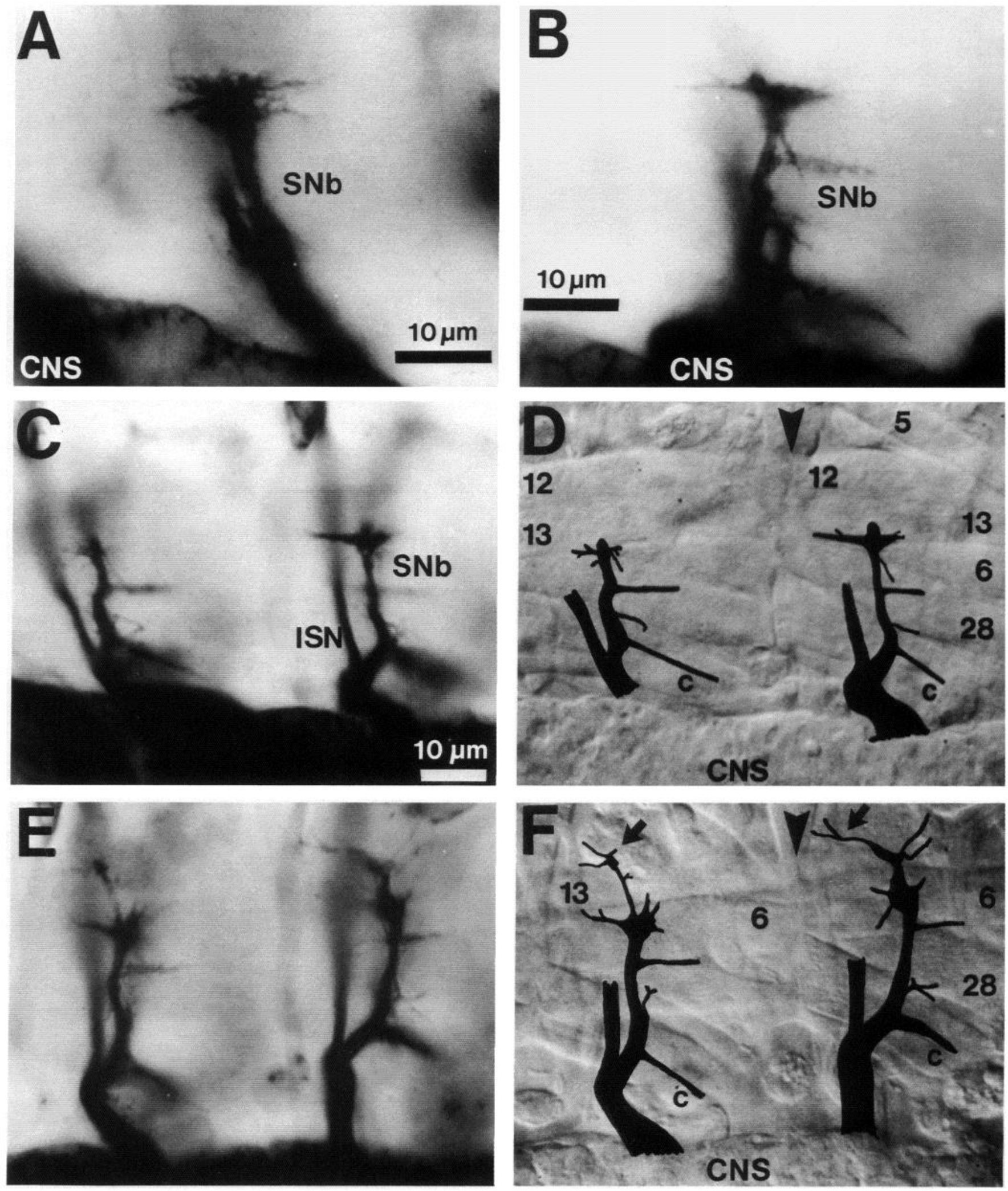

Figure 9. Development of the $\mathrm{SNb}$ branch. $A$, The first pioneer growth cones of the $\mathrm{SNb}$ in a late stage 15 embryo. $B$, The $\mathrm{SNb}$ in a stage 16 embryo. Growth cones are diverging toward individual muscle fibers. $C$ and $D$, The SNb in 2 adjacent segments in a stage 16 embryo. In $D$ a tracing of the nerve trajectories has been superimposed on a Nomarski image of the bodywall muscles (arrowhead indicates the segmental border). $E$ and $F$, The $\mathrm{SNb}$ at a slightly later stage than in $C$. A growth cone has been extended from the border of muscle fibers 6 and 13 toward a stereotypic location on muscle fiber 12 (arrows). In $F$ a tracing of the nerve trajectories has been superimposed on a Nomarski image of the bodywall muscle fibers (arrowhead indicates the segmental border). The Nomarski image in $D$ and $F$ does not depict all the muscle fibers in the region, since the plane of focus is on the axon fascicle, which grows wedged between the muscles. However, the location and identity of the indicated muscles were verified by comparing different focal planes. Scale identical for $C, D, E$, and $F$. The nerves were labeled with HRP antibody and visualized with fluorescein-conjugated secondary. 


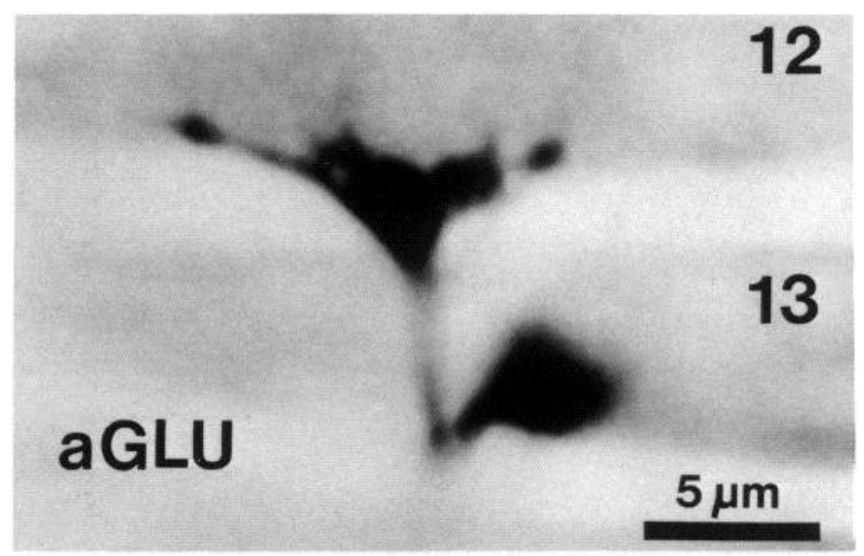

Figure 10. Neuromuscular endings on muscle fibers 12 and 13 labeled with glutamate antiserum $(a G L U)$ in a stage 16 embryo. Rhodamineconjugated secondary.

muscles at essentially the same time as the SN. As a result the pioneering of the 2 nerves allows growth cones to reach target muscle fibers throughout the segment synchronously. While the onset of synaptogenesis could result entirely from the precise timing and regulation of efferent outgrowth, it is also possible that its onset is triggered by a single commonly acting hormonal signal. The timing is late enough so that neuromuscular junctions are not functional and that no evoked contractions of muscle fibers occur before secretion of cuticle and hardening of the apodeme insertion sites, possibly preventing damage from premature muscle contractions.

Due to their staggered genesis, the ISN and the SN are pioneered over very different embryonic landscapes. Consequently, the growth cones of the 2 nerves may be encountering different kinds of guidance cues. Several factors that could govern the course of initial outgrowth of the ISN from the CNS include: (1) a dorsoventral gradient (Ghysen et al., 1986), (2) factors intrinsic to the pioneer neurons, (3) ectodermally derived landmarks within reach of the growth cone filopodia, and (4) selective cues from the muscle pioneers. Evidence for the last mechanism has been presented by Ball et al. (1985b) for peripheral pathfinding by motoneurons in the developing grasshopper. In the case of the $\mathrm{SN}$, however, the source of potential guidance cues seems more limited and is likely to be provided by the substrate of the fully differentiated muscle cells.

\section{Development of muscle fiber-specific neuromuscular junctions}

We have previously shown (Johansen et al., 1989) that the postembryonic muscle fibers of Drosophila are innervated by uniquely identifiable and anatomically stereotyped neuromuscular synapses. The neuromuscular endings on a specific muscle fiber possess several stereotyped features, including the nerve entry point, the innervated muscle fiber cell-surface domain, and the neurite branch anatomy. The specializations seen in larvae could in principle result from postembryonic muscle fiber-specific remodeling of generic neuromuscular contacts made on the embryonic fibers. However, the results from this study show that the stereotypic features seen in the larvae are actually due to precise projections laid down by the pioneering growth cones during embryogenesis, possibly in response to localized cellsurface features on the target muscle fibers. A significant feature in this context is that the muscle fibers are fully differentiated and are arrayed in their mature pattern before individual growth cones begin projecting onto their surfaces to form neuromuscular junctions. This suggests that the differentiation of the muscle fiber may be a prerequisite for the correct guidance and formation of the motoneuronal contacts and the establishment of subsequent trajectories. Growth cone filopodia approaching the muscle fibers can measure up to $15 \mu \mathrm{m}$ in length and are thus able to extend and potentially sample the full surface of a muscle fiber within a segment. The first growth cone contacts are made at stereotypic sites characteristic for each muscle fiber, which do not necessarily correspond to the location closest to the nerve branch. This suggests an active guidance mechanism, where growth cones seek out features residing on the muscle fiber surface.

We found that in Drosophila embryos the establishment of the initial motoneuronal projection to a muscle fiber is not achieved by trial and error or by significant remodeling. In each case we examined, the mature larval anatomy of the neuromuscular junction was reflected in the morphology of the earliest embryonic neuromuscular contacts, first apparent at $15 \mathrm{hr}$ of development. Also, while adjacent muscle fibers within a segment will bear anatomically quite different neuromuscular projections, homologous muscle fibers from segment to segment will possess essentially identical projections, suggesting that the guidance mechanisms are segmentally recapitulated. Our results suggest that the basic features of the mature third instar larval neuromuscular innervation pattern are formed over a period of about $1 \mathrm{hr}$ by the precise navigation and recognition by the innervating axons of their appropriate target muscle membrane surfaces.

The cellular mechanisms governing the establishment of this degree of stereotypy during synaptogenesis remain to be discovered. One likely mechanism might be the selective expression of "recognition" molecules on specific surface sites of the target muscle fibers. The ability of cells thought to be involved in axonal recognition events to precisely array such substances on their surfaces in vivo has been demonstrated in the mammalian spinal cord for the L1 and the TAG-1 glycoproteins (Jessel, 1988). The expression of these two molecules is both temporally and spatially regulated in different populations of spinal neurons, providing a possible mechanism for selective pathway choices (Dodd et al., 1988). Several other neuronal surface molecules expressed in a dynamic fashion on a subset of embryonic axons and neurons, and which have been proposed to be involved in neuronal recognition and axonal guidance, have been identified by monoclonal antibodies in grasshopper and Drosophila embryos (the fasciclins: Bastiani et al., 1987; Patel et al., 1987; Harrelson and Goodman, 1988; Zinn et al., 1988), and in the developing leech embryo (McKay et al., 1983; Johansen et al., 1985). We propose that a comparably precise and selective expression of such molecules on the target muscle fiber surfaces of Drosophila embryonic muscle fibers may account for the precision in the initial growth cone contacts.

\section{Transmitter expression}

Morphological and electrophysiological evidence suggests that each muscle fiber in dipteran larvae is innervated by at least 2 different axons (Hardie, 1976; Jan and Jan, 1976; Hardie and Osborne, 1977; Johansen et al., 1989). In this paper we show by double-labeling experiments with glutamate and HRP antibodies that all neuromuscular junctions of the larval bodywall musculature in Drosophila are probably glutamatergic. In ad- 

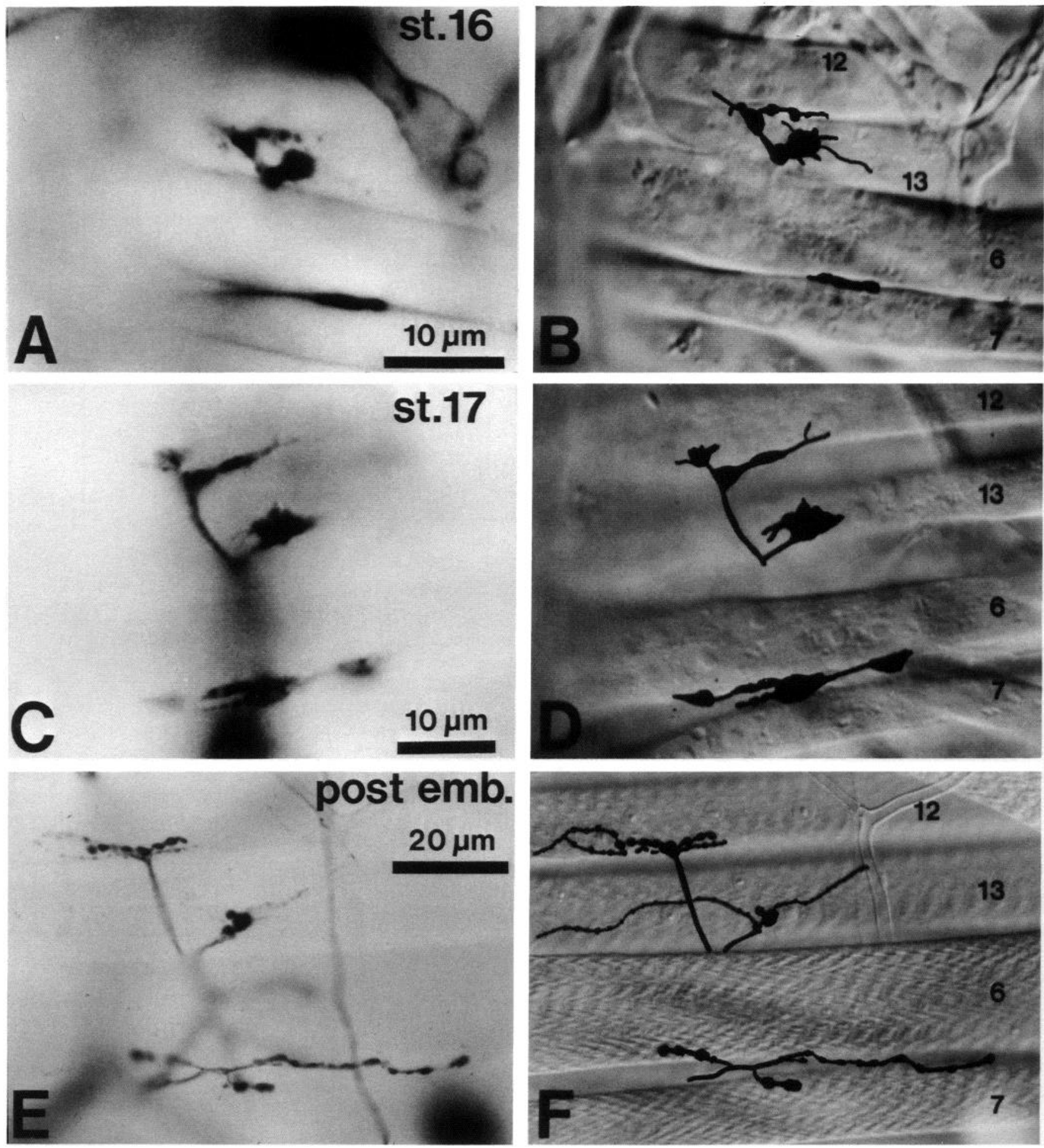

Figure 11. Development of neuromuscular junctions on muscle fibers $6,7,12$, and 13. $A$, $C$, and $E$, Neuromuscular junctions at 3 stages of development: stage 16 , stage 17 , and just after hatching (post emb.). $B, D$, and $F$, The corresponding Nomarski images of $A, C$, and $E$ with superimposed tracings of the nerve endings. The junctions were labeled with HRP-antibody and fluorescein-conjugated secondary.

dition, from immunocytochemical studies it is known that subsets of the junctions on specific muscle fibers express the neuropeptide proctolin (Anderson et al., 1988) and octopamine (Halpern et al., 1988). These neurotransmitters are therefore cotransmitters with glutamate, as has been proposed for other insect neuromuscular junctions (Adams and O'Shea, 1983; Worden et al., 1985).

The onset of glutamate immunoreactivity is closely correlated temporally to the initiation of spontaneous bodywall muscle contractions. The immunoreactivity is first observed in growth 
Figure 12. Developmental time scale of the events described in this paper. The figure is based on the description and staging of Drosophila embryonic development at $25^{\circ} \mathrm{C}$ given by CamposOrtega and Hartenstein (1985) combined with some of the observations of the present paper. The onset of axonogenesis is from Thomas et al. (1984) and Canal and Ferrus (1986).

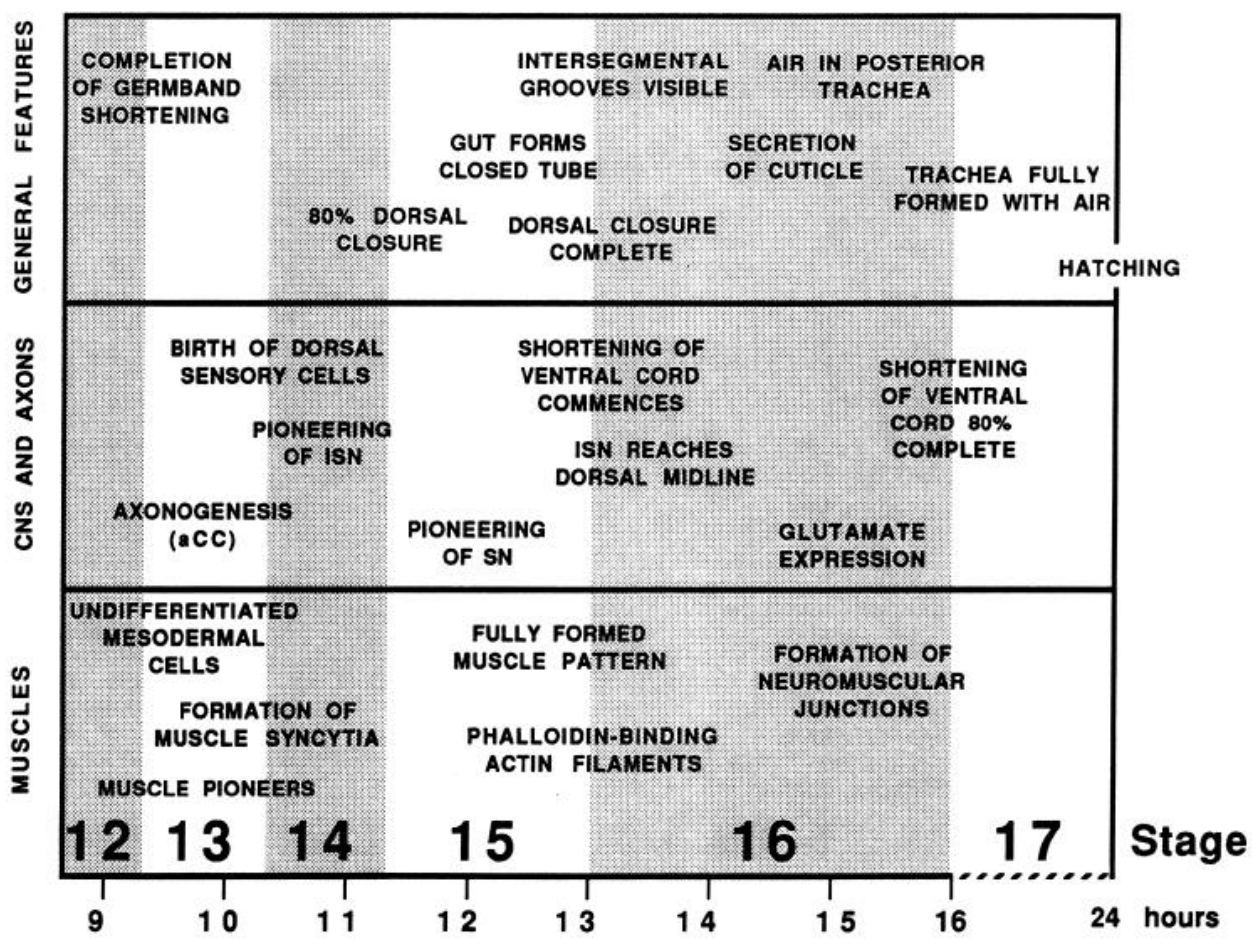

cones located on the muscle fiber surface, or in a few examples just before growth cones make their first contacts with the target. Evidence for growth cone expression of neurotransmitter in vitro has been found by Hume et al. (1983) and Young and Poo (1983) for explanted motoneuron-myofiber co-cultures. In these studies it was shown that acetylcholine could be released from growth cones and evoke postsynaptic responses in the contacted myoballs. It seems likely that similar excitation is occurring in Drosophila embryos. Whether postsynaptic activity plays an essential role in the correct establishment of motor synapses or their subsequent development in Drosophila remains to be determined.

\section{Muscle development}

In invertebrates the musculature is derived from a mass of mesodermally derived myoblasts lying in close apposition to the ectodermal epidermis. In insects (Ho et al., 1983; Ball et al., 1985a) some of these cells enlarge, become flattened, and develop growth cones which insert into the ectoderm delineating the future muscle insertion sites. These cells, which later fuse with the remaining smaller mesodermal cells and differentiate into muscle fibers, have been termed muscle pioneers by Ho et al. (1983). Our results suggest that the organization of the bodywall muscles in Drosophila larvae develops in a similar way. We have identified at $10 \mathrm{hr}$ of development bipolar cells with growth cone-like filopodia that extend their processes toward the future apodeme insertion sites along the segmental borders. These cells, which are located among the myoblasts, are good candidates for the muscle pioneers responsible for organizing the muscle pattern in Drosophila embryos. Cell manipulation or time-lapse micrographical analysis will be needed to establish the role of the putative muscle pioneers in muscle fiber development. It also remains to be determined whether there is one muscle pioneer per muscle fiber, or whether several muscle fibers can be derived from a single pioneer, as has been observed in grasshopper embryos. Using antibodies to the $\beta 3$ subunit of tubulin, Leiss et al. (1988) and Kimble et al. (1989) have also labeled, in whole-mount Drosophila embryos, early mesodermal cells which may include muscle pioneers.

A second feature of the developing musculature is the early and transient appearance of lateral dye coupling between the muscle fibers. Such coupling has been observed in both developing invertebrate and vertebrate muscle fibers (Dennis et al., 1981). The coupling in Drosophila embryos was limited to 3 or 4 adjacent fibers sharing common orientation and neighboring insertions. One purpose served by lateral coupling among functionally related fibers is to promote synchronous activation during early synaptogenesis, as seen in mammalian muscle development (Dennis et al., 1981). However, in Drosophila the muscle fibers are isolated from each other by late stage 15 , at least $1 \mathrm{hr}$ before synapses are made, ruling out this mechanism.

The prior differentiation and subsequent innervation of muscle fibers in embryos shows that muscle fibers are not dependent on motoneuronal innervation in order to undergo their normal fusion or patterning. This observation is in contrast to the proposal of Lawrence and Johnston (1986) for adult muscle development that motoneuronal innervation was essential for the development of a male-specific abdominal muscle. As the skeletal musculature is largely degraded during pupation without the corresponding degeneration of the motor nerves (Crossley, 1978; Costello and Wyman, 1986), it may be necessary for nerve projections in the pupae to be present for adult muscles to differentiate. This mechanism, however, is clearly not utilized for the correct differentiation of the muscle fibers during early embryogenesis.

In many vertebrates, the initial polyneuronal motor innervation of the neonate is reduced through synapse elimination to a single motoneuronal ending per muscle fiber (Redfern, 1970). This process is thought to be the result of competitive interactions between the innervating nerve terminals (for review, see 
Purves and Lichtman, 1985). The dynamic analysis of synaptic establishment and reorganization in vertebrates has recently been made possible using vital fluorescent probes (Lichtman et al., 1987) illuminating the changes that take place during the period of synapse elimination (Rich and Lichtman, 1989). In Drosophila, by contrast, we do not detect a comparable period of synaptic reorganization. Instead the mature ending morphology is rapidly attained soon after the first growth cone contacts. An additional difference between Drosophila and vertebrates is seen in the degree of morphological variability of the synaptic endings. While vertebrate endplates usually possess a general morphology and topography, each identified muscle fiber in Drosophila has a characteristic and stereotyped nerve ending morphology and innervation domain. However, some specific and selective nerve-muscle topography during development has been reported for the rat anterior serratus and diaphragm muscles (Laskowski and High, 1989).

In summary, we have described how precise and stereotyped neuromuscular junctions are established during embryonic development in Drosophila. These are rapidly generated over a period of approximately $3 \mathrm{hr}$ through an orchestrated sequence of specific axonal projections and site-specific muscle fiber contacts. Of particular significance is that at their targets the motoneuronal growth cones are capable of establishing selective and stereotyped projections over single cell membrane surfaces. While the cellular mechanisms governing this high degree of neuromuscular specificity remain unknown, one intriguing possibility is that each muscle fiber may express on its surface one or more specific surface labels, capable of guiding the motoneuronal growth cones.

\section{References}

Adams, M. E., and M. O'Shea (1983) Peptide cotransmitter at a neuromuscular junction. Science 221: 286-289.

Anderson, M. S., M. E. Halpern, and H. Keshishian (1988) Identifcation of the neuropeptide transmitter proctolin in Drosophila larvae. Characterization of muscle fiber-specific neuromuscular endings. J. Neurosci. 8: 242-255.

Ball, E. E., R. K. Ho, and C. S. Goodman (1985a) Muscle development in the grasshopper embryo. I. Muscles, nerves, and apodemes in the metathoracic leg. Dev. Biol. 111: 383-398.

Ball, E. E., R. K. Ho, and C. S. Goodman (1985b) Development of neuromuscular specificity in the grasshopper embryo: Guidance of motoneuron growth cones by muscle pioneers. J. Neurosci. 5: 18081819.

Bastiani, M. J., and C. S. Goodman (1986) Guidance of neuronal growth cones in the grasshopper embryo. III. Recognition of a specific glial pathways. J. Neurosci. 6: 3542-3551.

Bastiani, M. J., A. L. Harrelson, P. M. Snow, and C. S. Goodman (1987) Expression of fasciclin I and II glycoproteins on subsets of axon pathways during neuronal development in the grasshopper. Cell 48: 745755.

Bentley, D., and M. Caudy (1983) Navigational substrates for peripheral pioneer growth cones: Limb-axis polarity cues, limb-segment boundaries and guidepost neurons. Cold Spring Harbor Symp. Quant. Biol. 48: 573-585.

Bentley, D., and H. Keshishian (1982) Pathfinding by peripheral pioneer neurons in the grasshopper. Science 218: 1082-1088.

Campos-Ortega, J. A., and V. Hartenstein (1985) The Embryonic Development of Drosophila melanogaster, Springer, Berlin.

Canal, I., and A. Ferrus (1986) The pattern of early neuronal differentiation in Drosophila melanogaster. J. Neurogen. 3: 293-319.

Costello, W. J., and R. J. Wyman (1986) Development of an indirect flight muscle in a muscle-specific mutant of Drosophila melanogaster. Dev. Biol. 118: 247-258.

Crossley, A. C. (1978) The morphology and development of the Drosophila muscular system. In The Genetics and Biology of Drosophila,
Vol. 2b, M. Ashburner and T. R. F. Wright, eds., pp. 499-560, Academic, New York.

Dennis, M. J., L. Ziskind-Conhaim, and A. J. Harris (1981) Development of neuromuscular junctions in rat embryos. Dev. Biol. 81: 266-279.

Dodd, J., S. B. Morton, D. Karagogeos, M. Yamamoto, and T. M. Jessell (1988) Spatial regulation of axonal glycoprotein expression on subsets of embryonic spinal neurons. Neuron 1: 105-116.

Ghysen, A., C. Dambly-Chaudiere, E. Aceves, L. Y. Jan, and Y. N. Jan (1986) Sensory neurons and peripheral pathways in Drosophila embryos. Roux's Arch. Dev. Biol. 195: 281-289.

Giloh, H., and J. W. Sedat (1982) Fluorescence microscopy: Reduced photobleaching of rhodamine and fluorescein protein conjugates by $n$-propyl gallate. Science 217: 1252-1255.

Goodman, C. S., M. J. Bastiani, C. Q. Doe, S. du Lac, S. L. Helfand, J. Y. Kuwada, and J. B. Thomas (1984) Cell recognition during neuronal development. Science 225: 1271-1279.

Halpern, M. E., M. S. Anderson, J. Johansen, and H. Keshishian . (1988) Octopamine immunoreactive nerve terminals are found on a single identified muscle fiber of the Drosophila larval bodywall. Soc. Neurosci. Abstr. 14: 383.

Hardie, J. (1976) Motor innervation of the supercontracting longitudinal ventro-lateral muscles of the blowfly larva. J. Insect Physiol. 22: $661-668$.

Hardie, J., and M. P. Osborne (1977) The electrical and mechanical properties of supercontracting body-wall muscles of the blowfly larva, Calliphora erythrocephala (MEIG). Comp. Biochem. Physiol. 57A. 59-66.

Harrelson, A. L., and C. S. Goodman (1988) Growth cone guidance in insects: Fasciclin II is a member of the immunoglobulin superfamily. Science 242: 700-708.

Hartenstein, V. (1988) Development of Drosophila larval sensory organs: Spatiotemporal pattern of sensory neurones, peripheral axonal pathways and sensilla differentiation. Development 102: 869-886.

Hepler, J. R., P. Petrusz, and A. Rustioni (1986) Antisera to GABA, glutamate and aspartate: Characterization by immunoabsorption and immunocytochemistry. J. Histochem. Cytochem. 34: 110.

Hepler, J. R., C. Toomim, K. D. McCarthy, F. Conti, G. Battaglia, A. Rustioni, and P. Petrusz (1988) Characterization of antisera to glutamate and aspartate. J. Histochem. Cytochem. 36: 13-22.

Hertweck, H. (1931) Anatomie und Variabilităt des Nervensystems und der Sinnesorgane von Drosophila melanogaster (Miegen). Z. Wiss. Zool. 139: 559-663.

Ho, R. K., E. E. Ball, and C. S. Goodman (1983) Muscle pioneers: Large mesodermal cells that erect a scaffold for developing muscles and motoneurones in grasshopper embryos. Nature 301: 66-69.

Hume, R. I., L. W. Role, and G. D. Fischbach (1983) Acetylcholine release from growth cones detected with patches of AchR rich membranes. Nature 305: 632-634.

Jacobs, J. R., and C. S. Goodman (1988) Role of glia in the formation of axon pathways in the Drosophila CNS revealed by cell lineage markers and developmental mutants. Soc. Neurosci. Abstr. 14: 595.

Jan, L. Y., and Y. N. Jan (1976) Properties of the larval neuromuscular junction in Drosophila melanogaster. J. Physiol. (Lond.) 262: 189214.

Jan, L. Y., and Y. N. Jan (1982) Antibodies to horseradish peroxidase as specific neuronal markers in Drosophila and grasshopper embryos. Proc. Natl. Acad. Sci. USA 72: 2700-2704.

Jessel, T. M. (1988) Adhesion molecules and the hierarchy of neuronal development. Neuron 1: 1-13.

Johansen, J., I. Thompson, R. R. Stewart, and R. D. G. McKay (1985) Expression of surface antigens recognized by the monoclonal antibody lan 3-2 during embryonic development in the leech. Brain Res. 343: 1-7.

Johansen, J., M. E. Halpern, and H. Keshishian (1988) Development of muscle innervation in Drosophila embryos and larvae. Soc. Neurosci. Abstr. 14: 451.

Johansen, J., M. E. Halpern, K. M. Johansen, and H. Keshishian (1989) Stereotypic morphology of glutamatergic synapses on identified muscle cells of Drosophila larvae. J. Neurosci. 9: 710-725.

Keshishian, H. (1987) The cellular mechanisms that shape neuronal diversity and form. Insights from the embryonic grasshopper. In $\mathrm{Ar}$ thropod Brain: Its Evolution, Development, Structure and Functions, A. P. Gupta, ed., pp. 43-59, Wiley, New York.

Kimble, M., J. P. Incardona, and E. C. Raff (1989) A variant of 
$\beta$-tubulin isoform of Drosophila melanogaster ( $\beta 3)$ is expressed primarily in tissues of mesodermal origin in embryos and pupae, and is utilized in populations of transient microtubules. Dev. Biol. 131:415429.

Laskowski, M. B., and J. A. High (1989) Expression of nerve-muscle topography during development. J. Neurosci. 9: 175-182.

Lawrence, P. A., and P. Johnston (1986) The muscle pattern of a segment of Drosophila may be determined by the neurons and not by contributing myoblasts. Cell $45: 506-513$.

Leiss, D., U. Hinz, A. Gasch, R. Mertz, and R. Pohl-Renkawitz (1988) $\beta 3$ tubulin expression characterizes the differentiating mesodermal germ layer during Drosophila embryogenesis. Development 104: 525531.

Lichtman, J. W., L. Magrassi, and D. Purves (1987) Visualization of neuromuscular junctions over periods of several months in living mice. J. Neurosci. 7: 1215-1222.

McKay, R. D. G., S. Hockfield, J. Johansen, I. Thompson, and K. Frederiksen (1983) Surface molecules identify groups of growing axons. Science 222: 788-794.

Nardi, J. (1983) Neural pathfinding in developing wings of the moth Manduca sexta. Dev. Biol. 95: 163-174.

Patel, N. H. P. M. Snow, and C. S. Goodman (1987) Characterization and cloning of fasciclin III: A glycoprotein expressed on a subset of neurons and axon pathways in Drosophila. Cell 48: 975-988.

Purves, D., and J. W. Lichtman (1985) Principles of Neural Development, Sinauer, Sunderland, MA.
Redfern, P. A. (1970) Neuromuscular transmission in new-born rats. J. Physiol. (Lond.) 209: 701-709.

Rich, M. M., and J. F. Lichtman (1989) In vivo visualization of preand postsynaptic changes during synapse elimination in reinnervated mouse muscle. J. Neurosci. 9: 1781-1805.

Snow, P. M., N. H. Patel, A. Harrelson, and C. S. Goodman (1987) Neural-specific carbohydrate moiety shared by many surface glycoproteins in Drosophila and grasshopper embryos. J. Neuroscience 7: $4137-4144$.

Thomas, J. B., M. J. Bastiani, M. Bate, and C. S. Goodman (1984) From grasshopper to Drosophila: A common plan for neuronal development. Nature 310: 203-207.

Toomim, C., K. McCarthy, and P. Petrusz (1986) Characterization of antibodies to glutamate and aspartate by immunoblot analysis and immunohistochemistry. Soc. Neurosci. Abstr. 12: 419.

Worden, M. K., J. L. Witten, and M. O'Shea (1985) Proctolin is a cotransmitter for the SETi motoneuron. Soc. Neurosci. Abstr. 11: 327.

Young, S. H., and M. M. Poo (1983) Spontaneous release of transmitter from growth cones of embryonic neurons. Nature 305: 634 637.

Zinn, K., L. McAllister, and C. S. Goodman (1988) Sequence analysis and neuronal expression of fasciclin I in grasshopper and Drosophila. Cell 53: 577-587. 